

\title{
A pandemia COVID-19 em 3 atos: a visão de uma profissional de saúde
}

\author{
Ana Paula Santos
}

\section{Introdução}

Desde dezembro de 2019, uma pandemia tem causado reflexos na vida da população mundial. Um coronavírus, micro-organismo conhecido com causador de doenças respiratórias (Fung \& Liu, 2019), surgiu de forma diferente, causando mudanças de estilo de vida da população mundial (Bulut \& Kato, 2020).

Além das manifestações orgânicas, por vezes devastadoras, vividas pelas pessoas acometidas, a doença, que foi declarada uma pandemia pela Organização Mundial de Saúde (UNA-SUS, 2020), causou uma onda de sinais/sintomas psicológicos que afetaram um número maior de pessoas acometidas pela infecção. Entre essas pessoas, estão os profissionais de saúde. É estimado que um terço, ou até mesmo a metade da população possa apresentar consequências psicológicas e psiquiátricas caso não recebam cuidados adequados durante essa pandemia.

Neste artigo, a visão de uma profissional de saúde, embasada por dados científicos e por experiências vividas durante a pandemia será discutida, e pode ser encarada como um desabafo, um pedido de ajuda ou simplesmente como um dado científico.

\section{SARS CoV2 - 0 novo Coronavírus}

Os coronavírus são reconhecidos como causadores de infecções respiratórias leves a moderadas por mais de 50 anos (Fung \& Liu, 2019). No entanto, os vírus dessa família mais recentemente detectados, SARS CoV em 2002 e MERS CoV em 2012, mudaram completamente o entendimento conhecido sobre as infecções virais causadas por essa classe de micro-organismos, por causarem um grave comprometimento respiratório e surtos localizados da doença. Em dezembro de 2019, um novo coronavírus, nomeado SARS CoV-2 surgiu repentinamente em Wuhan, na China. Os primeiros casos da doença foram relacionados à exposição de morcegos em um mercado de animais na cidade (Bulut \& Kato, 2020).

A partir de sua identificação, a doença causada pelo SARS CoV-2 de 2019 (COVID-19) causou uma significativa mudança na vida da população global em virtude da sua elevada taxa de transmissibilidade e do seu potencial de gravidade, com consequente aumento das admissões hospitalares, esgotamento de leitos de terapia intensiva para o cuidado aos pacientes mais graves, e de mortalidade (Bulut \& Kato, 2020).

Em 31 de janeiro de 2020, a Organização Mundial de Saúde (OMS, 2020) declarou a COVID19 como sendo uma emergência de saúde pública de interesse internacional, ou seja, uma pandemia. Desde então, a doença afetou aproximadamente 53 milhões de pessoas distribuídas em 220 países, com mais de 1,2 milhão de mortes confirmadas. 


\section{A estrutura dramática de uma epidemia}

Segundo Charles E. Rosemberg, professor de História da Ciência e Medicina da Universidade de Harvard, as epidemias se comportam como peças teatrais, com um enredo de crescente e reveladora tensão, separados em três atos (Jones, 2020). No primeiro, os cidadãos ignoram os sinais de que algo está errado, talvez influenciados por um desejo de segurança ou necessidade de proteger interesses econômicos. O reconhecimento do avanço epidemiológico da doença e das mortes crescentes forçam o início do segundo ato do drama. Nesta fase, as exigências de explicações da doença geram respostas públicas, sejam técnicas, éticas e morais, ou não. Tem início então, o terceiro e último ato, que pode ser tão perturbador quanto a própria doença, repleto de crises de caráter individual e coletivo. Por fim, a cortina do palco de fecha e o espetáculo se encerra (Jones, 2020).

É nesse drama teatral que nos vemos agora, uma situação que, assim como a arte, potencializa experiências, sentimentos e emoções. Entre os protagonistas deste espetáculo estão o paciente, a equipe de saúde, a família e o governo.

Espera-se que, durante uma pandemia, a saúde física das pessoas bem como o combate ao agente etiológico dela, sejam os focos principais de todos (Ornell, Schuch, Sordi \& Kessler, 2020). Nesta pandemia, além desta constatação, observamos que a situação econômica mundial também esteve entre as principais preocupações (Cabral, Montibeler, Cabral, Prates \& Cordeiro, 2020), sendo a saúde mental, individual ou coletiva, subestimada e, por causa disso, aumentando ainda mais o potencial devastador da doença (Ornell, Schuch, Sordi \& Kessler, 2020).

É fato que uma vacina irá chegar e a doença perderá força. No entanto, as sequelas psicológicas de uma saúde mental negligenciada podem ser mais duradouras e prevalentes que a própria COVID-19, sendo capazes de afetar diferentes setores da sociedade (Ornell et al., 2020).

\section{O médico como um dos protagonistas}

Ao longo dos últimos nove meses tenho vivido essa experiência dentro de uma Unidade de Terapia Intensiva especializada em COVID-19 de um hospital privado no Rio de Janeiro, como médica intensivista. Entendo a vivência na pandemia COVID-19 como uma montanha russa. Para uns é excitante, libera adrenalina. Para outros, aterrorizante, gerando muito medo. Ou seja, as experiências vividas por cada ser humano são individuais e várias nuances de sentimentos se deslocam dentro deste cenário.

Há mais de 100 anos, desde a Gripe Espanhola, uma pandemia com esse comportamento de transmissibilidade, não era vivida por grande parte da população mundial (Teixeira, 1993). Antes da chegada da COVID ao Brasil, os médicos viveram o primeiro ato da metáfora utilizada por Rosemberg (Rosemberg, 1989, como citado em Jones, 2020), ignorando a doença. Aparentemente, não por medo ou proteção de interesses econômicos, e sim por manterem como prioridade as doenças de sua rotina profissional. A COVID-19, estaria ameaçando planos regionais para eliminar e controlar doenças infecciosas, incluindo tuberculose, HIV, hepatites, dengue, Zika e Chikungunya (OPAS, 2020). Pode 
ter sido este um dos motivos que justificou o questionamento sobre a importância que estavam dando à uma doença identificada do outro lado do mundo.

Naturalmente, a ignorância, principalmente para aqueles da ciência, gera uma busca incessante pelo estudo, pesquisa e conhecimento. Entretanto, apesar do critério na seleção de notícias e leituras, sejam elas científicas ou não, a desinformação e o consumo de matérias sensacionalistas, podem ter contribuído para uma mudança de sentimento - da ignorância para a ansiedade. Começamos, então, o segundo ato.

A avidez pelo entendimento das bases biológicas, fisiopatológicas, clínicas e de tratamento gerou uma enxurrada de publicações. Contudo, a alta produtividade científica como resposta à urgência imposta por uma pandemia, trouxe um questionamento sobre a qualidade dos artigos. De acordo com a Johns Hopkins Bloomberg School of Public Health (2020), a ansiedade em divulgar resultados de pesquisas relacionadas à COVID aumentou o número de submissões em plataformas preprint, que disponibilizam papers antes de uma rigorosa revisão, como acontece nos jornais científicos renomados.

As respostas e evidências fornecidas, independentes de sua confiabilidade, vieram ao encontro da angústia do médico, que tem entre as maiores gratificações inerentes à sua profissão o alívio da dor e do sofrimento, a cura de doenças, a possibilidade de salvar vidas, diagnosticar corretamente e sentir-se competente (Nogueira-Martins, 2003). A prescrição de algum tratamento contra esse vírus ainda pouco conhecido era uma forma de sentir-se menos impotente, ainda que qualidade, metodologia e boas práticas possam ter ficado em segundo plano.

Além de tratar sua angústia, muitos profissionais aceitaram e continuam aceitando como verdade absoluta resultados publicados que demonstrassem benefícios dessa ou daquela droga, ainda que gerassem eventos adversos e/ou um outro estudo revelasse a ausência de efetividade do medicamento (World Health Organization, 2020). Assim, cedem à pressão externa - do paciente, de sua família e até de governantes - por prescrever algo que acelere a cura ou que, pelo menos, encene algo como isso. Infelizmente, dessa maneira, pode ocorrer a quebra de um dos princípios mais importantes da bioética: "Primum non nocere", ou "Primeiro, não prejudicar" (Freitas, 1999).

O terceiro e último ato da pandemia COVID é repleto de ações e emoções na visão do médico. De acordo com Ornell et al (2020), o número de pessoas psicologicamente afetadas costuma ser maior que o de pessoas acometidas pela infecção. Entre essas pessoas, estão os profissionais de saúde e por que não dizer, todos os cidadãos. É estimado que entre um terço e a metade da população possa apresentar consequências psicológicas e psiquiátricas caso não recebam cuidados adequados durante essa pandemia (Lima, 2020).

Uma revisão sistemática realizada por Vindegaard e Benros (2020), sobre as consequências da saúde mental durante a pandemia COVID, incluindo 41 artigos, 20 dos quais relacionados à profissionais de saúde, revelou que nesta classe foi encontrado aumento de depressão / sintomas depressivos, ansiedade, sofrimento psicológico e distúrbios do sono. 
Fazendo um paradoxo com o que foi previamente mencionado neste texto, mas permitam-me dizer, não pejorativamente criticado, a saúde orgânica do profissional de saúde também deve ser discutida. Na verdade, é reconhecida a conexão entre saúde física (SF) e mental (SM) de modo geral, mas em se falando de profissionais de saúde, em especial de médicos, essa interação, incluindo também qualidade de vida (QV), foi avaliada em um estudo paulistano. As três variáveis estudadas integraram-se como se segue: QV favorável esteve associado com ter boa SF e SM, frequentar congressos regulamente, ter tempo suficiente de lazer e estar satisfeito com a profissão. SF boa ou muito boa associou-se independentemente com QV e SM positivas, faixa de renda mais alta, prática regular de atividades físicas e nunca ter fumado. SM favorável foi vinculada com satisfação profissional, tempo para lazer, e boa avaliação da QV e da SF (Torres, Ruiz, Müller \& Lima, 2011).

Uma vez justificada, sigo fazendo uma avaliação do binômio "saúde física e mental" de profissionais de saúde tendo a pandemia COVID como pano de fundo. Médicos, enfermeiros, técnicos em enfermagem, de laboratório ou radiologia, fisioterapeutas, nutricionistas, psicólogos, entre tantas outras profissões que integram uma equipe multidisciplinar da linha de frente no combate ao coronavírus, estão sob risco de consequências físicas e mentais (Shaukat, Ali \& Razzak, 2020). Neste grupo, longas jornadas de trabalho, contato próximo com pacientes com COVID, uso inadequado de equipamentos de proteção individual, entre outros fatores, estiveram associados com o adoecimento do próprio profissional. No mesmo estudo, foi observada a ocorrência de lesões cutâneas e feridas nasais em $97 \%$ e $83 \%$, respectivamente, como consequência ao uso de máscaras de proteção. Como exigir que, durante uma pandemia, os plantões sejam mais curtos, longe de ambientes de pacientes com COVID e mantendo uso de dispositivos que ferem e deixam marcas físicas e psicológicas? Os autores concluem que os profissionais de saúde apresentaram altos níveis de depressão, ansiedade, insônia e angústia.

Aos sintomas psicológicos desenvolvidos soma-se o medo, um dos sentimentos mais reportados por profissionais de saúde durante a pandemia COVID (Al Sulais, Mosli \& AlAmeel, 2020) e capaz de alimentar ainda mais os distúrbios mentais, tais como depressão e ansiedade. Dois estudos paquistaneses apresentaram a mesma conclusão, em que os principais motivos para justificar o medo foram a ausência de equipamentos de proteção individual para o trabalho com consequente preocupação em adoecer e transmitir a doença aos seus familiares (Arshad \& Islam, 2020; Urooj, Ansari, Siraj, Khan, \& Tariq, 2020).

Em duas ocasiões descritas neste texto, os equipamentos de proteção individuais foram mencionados e a eles devem ser somados todos os insumos necessários para o tratamento dos pacientes doentes, tais como medicamentos e respiradores, além da formação de equipes multiprofissionais capazes. Diante deste tópico, que mereceria uma peça ou drama teatral a parte, algumas emoções devem ser exploradas. Milagrosamente, profissionais de saúde foram contratados de forma emergencial, equipamentos de proteção individual surgiram de todos os lados, aparelhos de ventilação mecânica, bombas infusoras, monitores hemodinâmicos, aparelhos de gasometria e, 
inclusive hospitais inteiros, surgiram. Recursos financeiros para a estrutura direcionada ao serviço público de saúde vieram de doações de empresas privadas, mas também tiveram origem pública, o que nos causa certa surpresa tendo em vista o conhecimento do crônico caos da saúde pública. Em pouco tempo, investigações revelaram fraudes em licitações, roubos, prisões e delações. A despeito de todo o desvio de dinheiro público, o trabalho foi bem feito e muita gente se beneficiou. Foram então dois sentimentos: alívio pelas vidas salvas e decepção pela crueldade que a corrupção e a ganância causam.

Todo o processo de humanização dentro de um hospital e de um CTI (Bolela, 2008; Costa, Figueiredo \& Schaurich, 2009) foi por água abaixo com essa pandemia. O isolamento não foi só social. $\mathrm{O}$ doente por SARS CoV 2 também precisa ficar isolado, mesmo dentro de um hospital, sem contato físico direto com profissionais, sem poder circular pelos corredores do hospital, sem possibilidade de visitas. Isso fez com que fosse criada uma operação para fornecimento de notícias às famílias e amigos. A grande maioria dos hospitais criou uma estrutura onde um único contato ao dia era realizado por um profissional da equipe de saúde, passando um boletim médico. Nesse momento, um misto de sentimentos: frustração pela ausência de melhora e até pela piora do doente; raiva da situação vivida; alento e empatia ao ouvir mensagens emocionadas de agradecimento.

A despeito da histeria coletiva que tomou conta do mundo, a lucidez de todos esses profissionais foi necessária para que um bom trabalho fosse feito. Apesar de momentos de fraqueza que todo ser humano pode e deve ter, a sensação de que existe um outro, e que esse outro precisava de atendimento, fez com que medo, raiva, tristeza, ansiedade, frustração, angústia, decepção, fossem às vezes digeridos, e outras vezes deixados para ser sentidos "mais tarde, depois do plantão, depois do trabalho", pois naquele momento um outro precisava ser cuidado (Silva \& Teixeira, 2002). Mas existe uma hora em que este profissional também precisa ser tratado, seja com a alegria de estar entre pessoas queridas, seja praticando algum hobby, seja sendo tratado por uma equipe de saúde mental (Walton, Murray \& Christian, 2020). De acordo com Silva e Teixeira (2002):

A sociedade exige cada vez mais que o médico seja capaz de solucionar de maneira rápida eficiente e certeira todos os problemas que the são apresentados, desconsiderando as limitações humanas desse profissional. Estranhamente, essa forma de pensar e de agir é incentivada pela própria formação acadêmica, pois esta, faz com que o estudante de Medicina, futuro médico, acredite que possua qualidades quase sobre-humanas. Porém, ao deparar-se com a realidade limitadora do cotidiano, o médico já formado, frustra-se ao perceber a impossibilidade de esgotar toda a demanda que lhe é apresentada, na forma que Ihe é exigido. Dessa maneira, acaba desenvolvendo sentimentos de angústia profunda, decorrentes dessa frustração. Como seu status social desaprova a demonstração de sinais de dificuldade ou insegurança, o médico se auto proíbe de externalizar a angústia sentida, acabando por abafar seus sentimentos, sofrendo calado e isolado, construindo sua própria 
prisão, transformando-se em um ser que sofre, sem mostrar que sofre. (Silva \& Teixeira, 2002, p. 75)

E assim se encerra o último ato do drama que a pandemia COVID-19 instalou no mundo. Fato é, que a cortina não se fecha aqui. Ainda existe um longo caminho pela frente até que a doença física tenha sua cura ou uma vacina preventiva descoberta e amplamente disseminada. Quando isto acontecer, ainda restarão sequelas mentais significativas em todos aqueles que viram de perto, assistiram da primeira fila, este espetáculo.

\section{Uma experiência pessoal}

Ao longo de toda essa jornada pela qual estamos passando, eu, particularmente, passei por vários momentos. Alguns se sobrepuseram, alguns passaram, e outros persistem. Sentimentos conflitantes, percepções diferentes, valores questionados, posições tomadas, podem resumir tudo o que passou pela cabeça de uma médica pneumologista e intensivista no olho do furacão, e que pretendo dividir neste texto. Não que minha experiência seja diferente da de tantos outros profissionais de saúde, mas a forma como encaramos os fatos, isso sim, é individual.

Ignorância. Conforme afirmado acima, 100 anos nos separam da última pandemia. Num primeiro momento eu também me questionei sobre a ênfase dada à uma doença identificada na China.

Por que tanta atenção a um vírus novo e nenhuma ao bacilo da tuberculose, que mata há milênios, e que é meu objeto de atuação profissional, ensino e pesquisa?

Ansiedade. Conforme as notícias avançavam e a onda se aproximava, a mídia sensacionalista (ou realista?), mostrava o caos na saúde de países europeus, que teoricamente apresentavam uma melhor economia e possibilidades de investimento na saúde. Um cálculo simples foi suficiente para entender que, se não tínhamos leitos suficientes na saúde pública para as doenças já conhecidas, como seria com esse tsunami chegando? Aí bateu o medo e a ansiedade, porque as notícias chegavam, mas o vírus não... E sem data marcada para chegar, não estávamos preparados, protegidos...

Angústia. Ele chegou em março, e de uma hora para outra viramos uma Unidade COVID. Em apenas um dia, foram 20 internações na unidade. No mesmo final de semana, começaram as evoluções clínicas graves, que não tinham um padrão, uma receita de bolo... Conhecemos a happy hypoxia (Dhont, Derom, Van Braeckel, Depuydt, \& Lambrecht, 2020), ou a "hipóxia feliz", caracterizada por valores de oxigenação cada vez piores sem que os pacientes sentissem falta de ar... Antes que eles chegassem a um nível crítico, tínhamos que intubar e antes deste procedimento sempre conversávamos, explicando como seria... A resposta do paciente era sempre a mesma: "Se a senhora acha que tem que fazer, pode fazer! Confio em você!". Não havia um pedido para esperar, 
para tentar outra coisa... Todos muito resignados... Isso fazia parte da doença? Era desorientação pela falta de oxigênio no cérebro? Era medo?

Impotência. O "eu confio em você" pesava mais do que qualquer outra coisa... A expectativa da melhora rápida, como acontece em outras doenças conhecidas, não era uma realidade com o novo vírus. A depois de cada dia menos ruim, vinha um outro bem pior. E na cabeça ecoava o "eu confio em você!". Como confiar em mim se eu não sabia com o que estava lidando? Que bicho era esse, cujo único padrão que encontrávamos era radiológico e laboratorial? Todas as tomografias praticamente iguais, todos os exames laboratoriais revelando problemas na coagulação, mas cada paciente evoluindo de uma maneira diferente.

Princípios. Sobreposto ao sentimento de impotência que surgia, já que nada do que fizéssemos gerava uma resposta positiva consistente ou duradoura, veio a enxurrada de artigos científicos tentando dar as respostas que todos esperávamos. Em um curto espaço de tempo, milhares de artigos foram publicados, sendo impossível se manter atualizado com os 100 artigos publicados no dia anterior. Qualidade, metodologia, boas práticas foram questionadas, mas ainda assim, a angústia por alguma resposta, fez, e ainda faz, com que vários profissionais aceitem como verdade absoluta os resultados publicados que demonstrem benefícios dessa ou daquela droga. E se nossos governantes e alguns médicos verbalizam o "E daí que não foi comprovado cientificamente?" por que seria diferente com a população leiga, ávida por um elixir milagroso? A pressão por prescrever qualquer coisa agora não era só interna, de nós médicos querendo tratar nossa ansiedade, mas externa também, do paciente e de sua família. No entanto, durante minha formação da graduação, fiquei marcada pela frase: "Primum non nocere" (Freitas, 1999). Hidroxicloroquina, tocilizumabe, ivermectina? Não... Se não vai ajudar e pode prejudicar, não serei eu a prescrever.

Medo. Começamos a internar médicos e seus familiares. Todos evoluindo da mesma forma. Curiosamente, meu maior medo não era de adoecer e sim de transmitir a doença àqueles que são minha base. E se eu fosse a fonte da doença para meus pais, meu marido, e até amigos? Como conviver com essa responsabilidade?

Empatia. Pouco a pouco o processo de humanização criado pelas instituições hospitalares foi sendo substituído por um ambiente completamente fechado. O paciente, completamente isolado, não tinha como encontrar seus familiares. A ligação telefônica feita por um membro da equipe transmitia o boletim médico do dia a algum parente. Os sentimentos ficam misturados. À repetição do quadro do dia anterior, seguia-se a frustração familiar que esperava uma boa notícia. Era ruim falar sempre a mesma coisa, que não havia melhora, e que o quadro estava estável. Muitos familiares conseguiam compreender e aguentar a difícil passagem do tempo. Outros, ao contrário, movidos por todo tipo de sentimento, não conseguiam esconder a própria raiva gerada pela notícia. Entretanto, alguns conseguiam emocionar toda a equipe quando reconheciam e agradeciam o esforço que estava sendo montado diante dessa situação ímpar. 
Altruísmo e esperança. Em meio ao trabalho em uma instituição privada especializada em COVID-19, fui convocada para a mesma função em meu outro trabalho, agora um hospital universitário público, a fim de dividir a experiência adquirida. Exercer a medicina por amor. Não que estivesse fazendo aquilo de graça, ao contrário, é um emprego concursado e com salário, mas imaginava que fosse encontrar uma estrutura caótica, sem qualquer condição de trabalho. Não era a mesma coisa que um hospital privado, mas o que faltava em termos de estrutura, foi compensado com uma equipe sensacional, que me deu esperança...

Decepção. Milagrosamente, novos profissionais de saúde foram contratados e todo o material que sempre faltava começava a chegar, acrescido dos equipamentos específicos para o tratamento da COVID-19. A notícia sobre os recursos públicos investindo as unidades hospitalares foi logo seguida pelas notícias sobre as fraudes nas licitações e tudo o mais que acontece em situações assim. Mas, o trabalho que deveríamos fazer foi bem feito e muita gente se beneficiou. Eram então dois sentimentos: leveza pelas vidas salvas e decepção pela crueldade que a corrupção e a ganância causam.

Lucidez. A despeito da histeria coletiva fomentada pela imprensa, amigos, grupos de mensagens, eu me mantive lúcida. Confesso que tenho sido muito privilegiada, pois não tive a doença, minha família está bem e meus locais de trabalho, pesando a diferença entre hospital público e privado, foram bem estruturados. Mas por trás dessa minha lucidez tive, e tenho até agora, momentos de fraqueza. Ainda falta algum tempo para que consigamos enxergar uma luz no fim do túnel e um retorno à normalidade.

Falta chegar o sentimento de alívio, que espero. Estamos ainda no meio de tudo isso. Talvez, as mesmas experiências que vivi possam ter gerado percepções e sentimentos diferentes em outros profissionais, mas para mim, tem sido desgastante, no entanto é apenas mais uma experiência.

\section{Conclusão}

Um novo tempo vai chegar... Tempo em que essa pandemia terá passado, seja através da prevenção criada por uma vacina ou através de um tratamento acelerando a cura. As marcas físicas passarão, mas a saúde mental terá sofrido um grande impacto e todas as sequelas psicológicas permanecerão, seja naqueles que viveram a doença "na pele", seja naqueles que combateram o vírus como profissionais de saúde. A forma como cada um desses profissionais está lidando com todas as emoções vividas neste período terá um reflexo na relação com os pacientes e consigo próprio e muito ainda será estudado, pesquisado, publicado e conhecido sobre as marcas emocionais de uma pandemia.

\section{Referências bibliográficas}


Al Sulais, E., Mosli, M., \& AlAmeel, T. (2020). The psychological impact of COVID-19 pandemic on physicians. Saudi Arabia: A cross-sectional study. Saudi J Gastroenterol. 26(5), 249-255. doi: 10.4103/sjg.SJG_174_20.

Arshad, A. R. \& Islam, F. (2020). COVID-19 and Anxiety amongst Doctors: A Pakistani Perspective. J Coll Physicians Surg Pak. 30(10), 106-109.

Bolela, F. (2008). A humanização em terapia intensiva na perspectiva da equipe de saúde. (Dissertação de mestrado). Escola de Enfermagem de Ribeirão Preto da Universidade de São Paulo - USP, São Paulo, SP, Brasil. Recuperado de https://www.teses.usp.br/teses/disponiveis/22/22132/tde-07072008-

\section{3/publico/FABIANABOLELA.pdfv}

Bulut, C., \& Kato, Y. (2020). Epidemiology of COVID-19. Turk J Med Sci. 21;50(SI-1), 563-570. doi: 10.3906/sag-2004-172.

Cabral, J. A., Montibeler, E. E., Cabral, M. V. De F., Prates, T. M., \& Cordeiro, D. R. (2020). Impacto econômico do COVID-19 sobre a estrutura produtiva do Estado do RJ. Revista Econômica. 22 (1). doi: https://doi.org/10.22409/reuff.v22i1.43263

Costa, S. C., Figueiredo, M. R. B., \& Schaurich, D. (2009). Humanização em Unidade de Terapia Intensiva Adulto (UTI): compreensões da equipe de enfermagem. Interface - Comunicação, Saúde, Educação, 13(Suppl. 1), 571-580. https://dx.doi.org/10.1590/S141432832009000500009

Dhont, S., Derom, E., Van Braeckel, E., Depuydt, P., \& Lambrecht, B. N. (2020). The pathophysiology of 'happy' hypoxemia in COVID-19. Respir Res. 28;21(1), 198. doi: 10.1186/s12931-020-014625.

Freitas, E. J. D. (1999). Primun Non Nocere. Recuperado de https://portal.cfm.org.br/artigos/primumnon-nocere/ .

Fung, T. S., \& Liu, D. X. (2019). Human Coronavirus: Host-Pathogen Interaction. Annu Rev Microbiol 8;73, 529-557. doi: 10.1146/annurev-micro-020518-115759.

Johns Hopkins Bloomberg School of Public Health. (2020). Preprints and peer review in a pandemic. Recuperado de https://www.jhsph.edu.

Jones, D. S. (2020). History in a Crisis - Lessons for Covid-19. N Engl J Med. 30;382(18), 1681-1683. doi: $10.1056 /$ NEJM p2004361.

Lima, R. C. (2020). Distanciamento e isolamento sociais pela Covid-19 no Brasil: impactos na saúde mental. Physis. 30(2), 214-300.

Nogueira-Martins, L. A. (2003). Mental health of health care workers. Rev Bras Med Trab. 1(1), 59-71.

Organização Panamericana de Saúde. (2020). COVID-19 ameaça controle e eliminação de doenças infecciosas nas Américas. Recuperado de https//:www.paho.org. 
Ornell, F., Schuch, J.-B., Sordi, A. O. \& Kessler, F. H. P. (2020). "Pandemic fear" and COVID-19: mental health burden and strategies. Braz J. Psychiatry. 42(3), 232-235. Recuperado de http://dx.doi.org/10.1590/1516-4446-2020-0008.

Shaukat, N., Ali, D. M. \& Razzak, J. (2020). Physical and mental health impacts of COVID-19 on healthcare workers: a scoping review. Int J. Emerg Med. 13 (1), 40.

Silva, A. L. P. \& Teixeira, M. A. A. (2002). A angústia médica: Reflexões acerca do sofrimento de quem cura. Revista Cogitare Enfermagem. 7, n.1, 75-83. Curitiba. Recuperado de https://revistas.ufpr.br/cogitare/article/view/32560/20665 .

Teixeira, L. A. (1993). Medo e morte: sobre a epidemia de gripe espanhola de 1918. Rio de Janeiro: Universidade do Estado do Rio de Janeiro/Instituto de Medicina Social, 1993. 32p. Série Estudos em Saúde Coletiva, n.59.

Torres, A. R., Ruiz, T., Müller, S. S. \& Lima, M. C. P. (2011). Qualidade de vida e saúde física e mental de médicos: uma autoavaliação por egressos da Faculdade de Medicina de Botucatu - UNESP. Rev Bras Epidemiol. 14(2), 264-275.

UNA-SUS (2020). Organização Mundial da Saúde declara pandemia do novo coronavírus. Ascom SE/UNA-SUS. March 11, 2020. Recuperado de https://www.unasus.gov.br/noticia/organizacaomundial-de-saude-declara-pandemia-de-

coronavirus\# : :text=Organiza\%C3\%A7\%C3\%A30\%20Mundial\%20de\%20Sa\%C3\%BAde $\% 20 \mathrm{~d}$ eclara\%20pandemia\%20do\%20novo\%20Coronav\%C3\%ADrus,-

Mudan\%C3\%A7a\%20de\%20classifica\%C3\%A7\%C3\%A3o\&text=Tedros\%20Adhanom\%2C\%20 diretor\%20geral\%20da,Sars\%2DCov\%2D2).

Urooj, U., Ansari, A., Siraj, A., Khan, S. \& Tariq, H. (2020). Expectations, Fears and Perceptions of doctors during Covid-19 Pandemic. Pak J Med Sci. 36 (COVID19-S4), S37-S42.

Vindegaard, N. \& Benros, M. E. (2020). COVID-19 pandemic and mental health consequences: Systematic review of the current evidence. Brain Behav Immun. 89, 531-542.

Walton, M., Murray, E. \& Christian, M. D. (2020). Mental health care for medical staff and affiliated healthcare workers during the COVID-19 pandemic. Eur Heart J Acute Cardiovasc Care. 9(3), 241-247.

World Health Organization. (2020). Clinical Management of COVID-19. Recuperado de http://who.int. 
Citação/Citation: Santos, A.P. (mai. 2020 a out. 2020). A pandemia COVID-19 em 3 atos: a visão de uma profissional de saúde. Revista aSEPHallus de Orientação Lacaniana, 15(30), 06-17. Disponível em www.isepol.com/asephallus. Doi:_10.17852/1809-709x.2020v15n30p06-17

Editor do artigo: Tania Coelho dos Santos.

Recebido/Received: 04/03/2020 / 03/04/2020.

Aceito/Accepted: 04/20/2020 / 20/04/2020.

Copyright: (c) 2019 Associação Núcleo Sephora de Pesquisa sobre o moderno e o contemporâneo. Este é um artigo de livre acesso, que permite uso irrestrito, distribuição e reprodução em qualquer meio, desde que o autor e a fonte sejam citados/This is an open-access article, which permites unrestricted use, distribution, and reproduction in any medium, provided the author and source are credited. 